IRA-International Journal of Education \& Multidisciplinary Studies

ISSN 2455-2526; Vol.04, Issue 03 (2016)

Pg. no. 355-358

Institute of Research Advances

http://research-advances.org/index.php/IJEMS

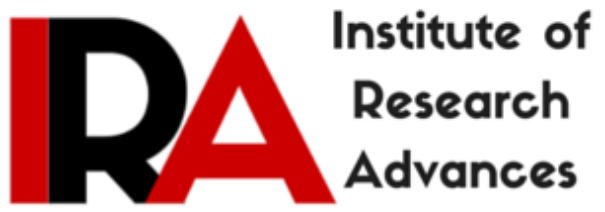

\title{
Development of Animal Husbandry and Dairying in Second Five Year Plan (1956 to 1961)
}

Dr. Kusum Kumari

Research Scholar, Izatnagar, Bareilly, UP-243122, India.

Type of Review: Peer Reviewed

DOI: http://dx.doi.org/10.21013/jems.v4.n3.p1

\section{How to cite this paper:}

Kumari, K. (2016). Development of Animal Husbandry and Dairying in Second Five Year Plan (1956 to 1961). IRA International Journal of Education and Multidisciplinary Studies (ISSN 2455-2526), 4(3), 355-358. doi:http://dx.doi.org/10.21013/jems.v4.n3.p1

(C) Institute of Research Advances

(cc) EY-NC

This work is licensed under a Creative Commons Attribution-Non Commercial 4.0 International License subject to proper citation to the publication source of the work.

Disclaimer: The scholarly papers as reviewed and published by the Institute of Research Advances (IRA) are the views and opinions of their respective authors and are not the views or opinions of the IRA. The IRA disclaims of any harm or loss caused due to the published content to any party. 
After independence in 1947, the Government of India started organized plan for the development of the country. Visible impact was not felt during the $1^{\text {st }}$ plan period. Regular famine, division of country created a situation where supply of food to country men was a major problem before the Government. According during the second five year plan emphases was given on the development of agriculture and animal husbandry sectors. The second five year plan started in 1956. An outlay of Rs 56 crores was provided by the Government of India for development of animal husbandry and dairying. The object of animal husbandry programme was to supply milk, meat and eggs in order to balance the customary Indian diets and to provide bullock power for agricultural operations.

In addition to by Products of agricultural food crops, residuesgrazing areas had been the main stay for cattle. Increase in the requirements of agriculture land for food production for the human population, development of industries road \& buildings grazing areas have steadily diminished. Cattle raising had to undergo a basic change in the sense that its future would depend on mixed farming system. Most of the fodder have to be grown on the holding of the farmers.

With the passage of time famine and epidemics have been largely brought under control and therefore a tendency for the number of cattle to increase further it was expected to become more marked due to total ban on slaughter of cattle. Proposal of total ban on slaughter of cattle derived from a widely prevalent religious sentiment which has been expressed in the constitution. The article 48 of the constitution prescribes that the states shall endeavor to organize agriculture and animal husbandry on modern and scientific lines and shall in particular, take steps for improving the breeds and prohibiting the slaughter of cows and calves and other milch and draught cattle.

An expert committee on the Prevention of slaughter of cattle was appointed by the government of India in 1954 to suggest measures to check the deterioration of cattle. The committee came to the conclusion that the present fodder was inadequate for maintaining the existing cattle population. The complete ban on slaughter of cattle would lead to increase in the number of productivecattle and cattle population will increase at the rate of $6 \%$ per annum. Such trends were already noted in 1953 in Uttar Pradesh by the Gosambardhan inquiry committee, which estimated that fodder and cattle feeding resources available were sufficient only for 58 percent of the cattle population. During the $2^{\text {nd }}$ plan it was proposed to set up 60 gosadans for about 30,000 cattle.

During the second five year plan it was proposed to implement scheme of livestock improvement through selected goshalas. The unproductive cattle from goshalas were to be sent to Gosadans.In gosadan animalswere likely to pass through nature death and fewGosandan proposed facilities of utilization of hides, bones and other products of natural fallen animals. The all India Khadi and village Industries Board had a number of Programme in this field. Each goshala was provided by the Government with certain number of animals of improved breed and was expected to secure an equal number from its own resources. About Rs 1 crore was provided for this scheme.

\section{Cattle Breeding Policy and Programmes:}

Among 25 well defined breeds of cattle and 6 well defined breeds of buffaloes in India few are of dairy type in which the females yield a large quantity of milk while the males are poor for work they are mostly found in their home tract. A large majority of the breeds are to the draught type in which the cows are poor milkers but the bullocks are of high quality. In between, there are many breeds, which is called dual purposes in which females yield more then an average quantity of milk, while the males are good working bullocks. These well defined breeds are found in the dry parts of the country outside there areas, over large parts of the country in the south of India, where rainfall is very heavy, the cattle are nondescript and do not belong to any breed. 
To obtain good result, an all India breeding policy has been drawn up by the Indian Council of Agricultural Research and accepted by the central and state government. This was briefly as follows:-

(a) In the case of well definedmilch breeds the milking capacity should be developed to the maximum by selective breeding and the maleprogeny should be used for the development of the non descript cattle.

(b) In the case of well defined draught breeds, the objective was to increase their milk without reducing their quality for work. Thus breeding policy was generally designed to increase the production of milk in the country without affecting the supply of bullocks for cultivation. In every draught breed there was always a small number which gave more than an average quantity of milk. By selecting bulls from this group the milk Production on the population can then be gradually increased by further selection and breeding. When this was to be done in the interior of the breeding tracts, the bulls produced were to be used in the outer areas to bring general improvement in the entire population.

For the implementation of this policy, each state was divided in to zones according to the breeds used in them. Thus in the district of Ahmadabad, Kaira, Broach and Surat, the breed used was Kankrej. In the western tracts of Uttar Pradesh like Saharanpur, Muzaffarpur, Aligharh, Mathura, etc.Hariana breed was used. In the hilly tracts such as Deheradun, Garhwal, Almora and Nainital, the breed used was Red Sindhi.

The State Government pursued the livestock improvement through key village scheme. The work envisaged castration of a scrub bulls, breeding operations controlled by artificial insemination centres, rearing of calves on a subsidized basis, development of fodder resources and the marketing of animals husbandry products organized on co-operative lines. During the second plan 1258 key village 245 extension centres were setup. This programmes was intended to produce about 22,000 improved stud bulls, 950,000 improved bullocks and one million improved cows.

Supply of milk to urban areas was a problem Large number of dairies in urban areas under were in unhygienic conditions and was danger to public health. Much of the milk sold in towns was adulterated and of poor quality. During the second five year plan proposal was given to organize 36 urban milk supply schemes, 12 co-operative creameries and 7 milk drying plants. The milk drying plants were to be located in rural areas to produce butter, ghee and skimmed milk powder. The general policy was that milk producer's co-operatives should be organized in village to supply milk to the urban milk supply schemes, creameries and milk drying plants. The milke producers were given assistance such as payment of remunerative price, provision of bulls or artificial insemination, technical advie, facilities for improving production, storage of fodder and provision of milking sheds. Milk collected from rural areas was to be distributed in urban areas under the control of milk boards. In Bombay (now Mumbai) a large milk colony was organized at Aarey and in Calcutta (Kolkota) at Haringhata. In these cities there were large concentrations of cattle which had to be removed out of town. Large scale milk schemes were produced to be taken up in Delhi and Madras. Distribution of toned milk as a cheap supply was also proposed in urban areas through the milk schemes.

\section{Control of diseases:}

In the second five year plan 1900 veterinary dispensaries including 145 mobile dispensaries were opened. The aim was toeradicateRinderpert, Foot and Mouth, Haemorrhogicsepticaemia, Black Quarter and Anthrax diseases. From 1954 to 1957 Dr. Lakshmi Sahai worked as director of the Indian Veterinary Research Institute from 1957 to 1964 he remained on the post of Animal Husbandry Commissioner, Government of India. Dr. Lakshmi Sahai died on $3^{\text {rd }}$ July, 1971. In 1957 Dr. N.D. Kehar took over as 
officiating Director of Indian Veterinary Research Institute till the post was occupied by Dr. P.G. Pandey whoremained as Director IVRI until 1960. There was a sever epidemic of African horse sickness in 1960. To control there diseases vaccines were prepared at the Biological products Division of the Indian Veterinary Research Institute.

The military and other horses and panics were immunized with this vaccine in order to control the dreaded diseases.

\section{Sheep:}

At the beginning of the second five year plan there was about 38 million sheep in India which produced around 60 million Pounds of wool per year. About 24 million pounds of the indigenous raw wool to the extant of 11 million pounds per year were imported. Improved variety of sheep was expected to yield 6 pounds of wool per year against 2 pounds per year from in digamous variety.

During the second five year plan new sheep breeding farms were established in Himachal Pradesh, Madhya Bharat and Saurashtra. In addition 396 sheep and wool extension centresand been established indifferent regions. The plan provided Rs 1.5 crores for sheep and wool development.

\section{Poulty:}

During the second five year plan it was proposed to set up four regional farms, each with 2000 laying hens for acclimatizing exotic breeds and from which foundation stocks could be distributed to 300 extension centres. Each extension centre had a demonstration unit with a development block attached to it. Private poultry breeders were trained at these demonstration units and the centre had a unit for defertilization of eggs from villages so that their shelf life could be increased especially in summer season. Experiments had shown that white leghons and Rhode Island Reds were the most useful breeds for crossing or upgrading the indigenous stock.

\section{Research and Education:}

In the second five year plan standardization division was opened at the Indian Veterinary Research Institute for regulating and controlling the quality and use of vaccines and sera prepared at different centres in the country.

The Government of India proposed to develop for research institutes namely temperate (Himalayan), dry (Northern), eastern and southern regions to investigate into problems of nutrition in those climates.

Programmes for key villages in national extension and other areas, rinderpert eradication and urban and rural milk supply schemes, required a total of about 5000 Veterinaries against 2750 likely to become available from existing institutions. To tide over this shortage double sifts were introduced in five Veterinary colleges at Hissar, Hyderabad, Patna, Bombay and Bikaner and four new colleges were set up in Madhya Bharat, Orissa, Andhara and Travancore-Cochin. A Postgraduate Veterinary college was setup at Izatnagar at the Indian Veterinary Research Institute. Since the veterinary degree course extended over four years, to meet shortage in the intervening period and emergency course of two years duration was started at 10 centres each admitting about 100 students. In a number of states special training courses in artificial insemination,, Poultry husbandry, Flaying and utilization of carcasses were instituted. A veterinary College was established at Pantnagar in Uttar Pradesh in 1960.

\section{REFERENCES}

Draft, Second Five Year Plan, Planning Commission, Govt of India, New Delhi. 